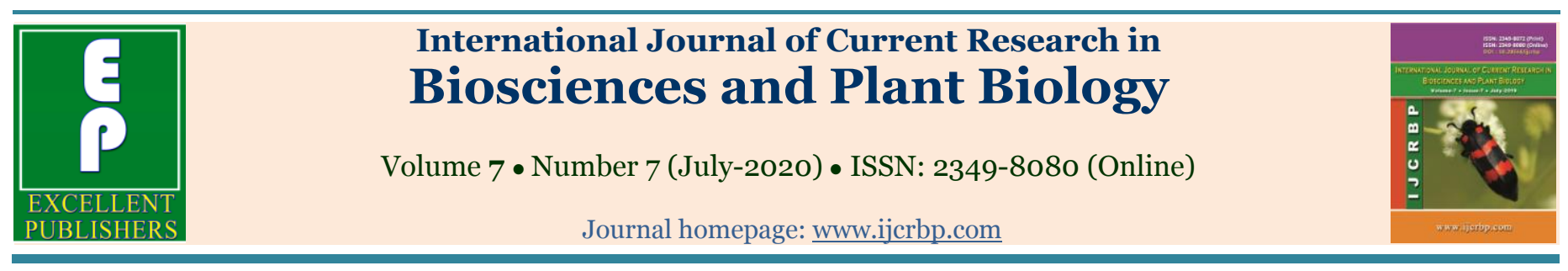

\title{
Association between Egyptian calves performance and growth hormone and IGF-1 levels under different housing types
}

\author{
Ahmed Mohamed Abd El-Hafeez, Sameeh Mohamed Zahed and \\ Mahmoud Yassin Mohamed*
}

\begin{abstract}
Animal Production Research Institute (APRI), Agricultural Research Center (ARC), NC 12618, Dokki, Giza, Egypt
*Corresponding author; e-mail: dr.yassin2005@gmail.com
\end{abstract}

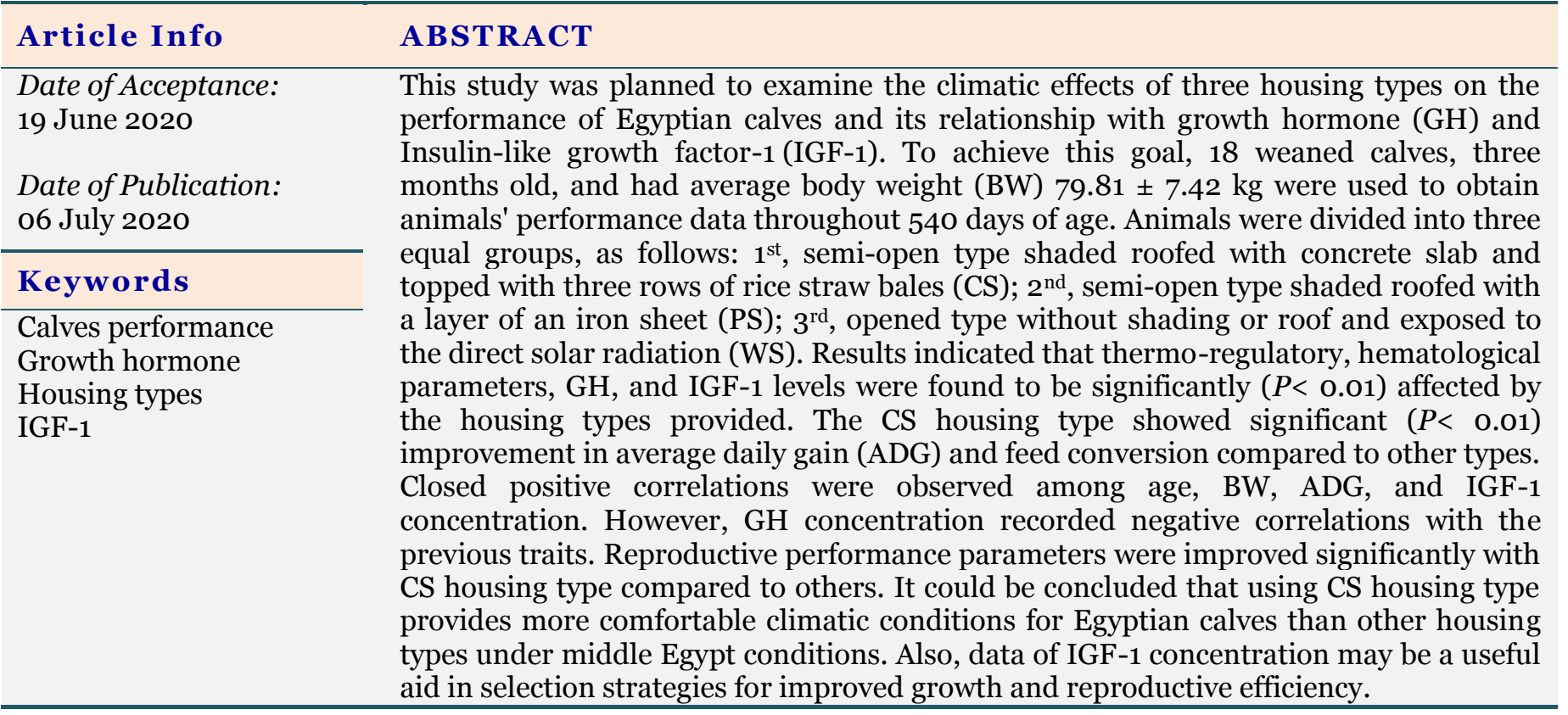

\section{Introduction}

Many types of animal housing were applied in middle Egypt. These types are closed, semiopened, or open with or without an umbrella. Materials used for awning roofs also varied, whether a concrete, iron sheet or asbestos. Several methods are also used to protect surfaces from direct solar radiation, such as placing rice straw bales on the surface, which has a positive effect on the micro-environment within the animal, and subsequently their productivity and fertility. The livelihood of animals under a concrete roof and topped by the breeder's house reduces the temperature of the roof, and this is reflected in the efficiency of respiratory rate and heat dissipation of animals to maintain their biological activity (Omran et al., 2019). The climate in middle Egypt is characterized by high ambient temperature (AT) and relative humidity (RH), especially in summer. 
Heat stress occurs when body temperature rises due to excessive metabolic heat production, increased ambient temperatures, or low heat loss (Silva et al., 2007). Hence, many productive and reproductive parameters, such as fertility, weight gain, feed intake, and milk production, can be penetrated. There are numerous climate stresses like heat, cold, rain, wind, and humidity, which can alter the endocrine system and animal performance such as natural cycle and reproductive system (Gaughan and Cawsell-Smith, 2015). Humam et al. (2019) declared that heat stress is still a major problem in animal production systems, and has harmful effects on animal health and productivity. Heat stress influences the hypothalamic-pituitary axis and the prosthetic system to initiate and adjust most activities (Tilbrook et al., 2000). Bhimte et al. (2018) stated that hyperthermia causes a rapid enhance in circulating growth hormone (GH) levels. Additionally, IGF-1 concentration decrease through summer season, which leads to the bad reproductive performance of heifers. Reducing IGF-1 can mediate the effect of decreasing feed intake because cows in negative energy balance have a lower IGF-1 rate (Bousquet et al., 2004).

The growth rate is mainly regulated by the somatotrophic axis, which consists of $\mathrm{GH}$, upstream hypothalamic hormones, IGF, and downstream signaling molecules (Munoz et al., 2011). Besides, GH and IGF-1 have both independent and combined effects, their influence through controlling metabolism and animal production. The pituitary gland synthesizes $\mathrm{GH}$, which acts immediately on the liver and fatty tissue to coordinate glucogenesis, lipogenesis, proteosynthesis, lipolysis, and insulin excretion by binding to GH-receptors (Yang et al., 2019). Also, the liver synthesizes IGF-1 that regulates all organs function. It performs an essential role in many physiological processes, enhances feed conversion, and boosts proteosynthesis (Gao et al., 2006). IGF1 binds to IGF-factor that binding protein-3 to influence the development, growth, and animals' reproduction (Othman et al., 2014).

Low information about Egyptian calves is available on growth patterns and reproductive performance under different housing types used in middle Egypt. Therefore, this study aimed to investigate the effect of housing type on calves' performance and its relationship to $\mathrm{GH}$ and IGF-1 levels.

\section{Materials and methods}

The present study was conducted during the period from May 2015 until August 2016 at Sids Experimental Station belonging to APRI, ARC, located at Beni-Suef Governorate in middle Egypt.

\section{Animals and experimental design}

Eighteen of Egyptian weaned male calves, three months old and averaged $79.81 \pm 7.42 \mathrm{~kg}$ BW were assigned to three equal groups housed under three housing types as follow: $1^{\text {st }}$, Semi-open shaded (20.0 m length $\times 20.0 \mathrm{~m}$ width $\times 3.5 \mathrm{~m}$ height) roofed with concrete slab, $40 \mathrm{~cm}$ thick and topped with three rows of rice straw bales and natural earthen ground with north-south direction(CS); $2^{\text {nd }}$, Semi-open shaded $(20.0 \mathrm{~m}$ length $\times 20.0 \mathrm{~m}$ width $\times 3.5 \mathrm{~m}$ height) roofed with a layer of iron sheet and natural earthen ground with west-east direction (PS); and the $3^{\text {rd }}$, the open type $(20.0 \mathrm{~m}$ length $\times 20.0 \mathrm{~m}$ width)without shading or roof and exposed to direct solar radiation and natural earthen ground with north-south direction(WS). All calves were fed individually on a total mixed ration consisted of $60 \%$ concentrate mixture, $20 \%$ clover hay, and $20 \%$ rice straw (Table 1), according to NRC (2001) requirements for growing calves. Fresh-water and minerals were available at all times. All animals were kept in the good hygienic condition during the experimental period. Individual calf weights were obtained at 30-day intervals from 90 to $540 \mathrm{~d}$ of age. Averages of daily gain, feed intake, and feed conversion were determined individually.

\section{Thermo-regulatory parameters}

Weather measurements were recorded in the tested housing types from 6:00 to 8:00 am and 12:00 to 14:00 pm Ambient temperature (AT, ${ }^{\circ} \mathrm{C}$ ) and relative humidity (RH, \%) were recorded simultaneously while measuring the physiological responses of the experimental animals. The temperature-humidity index (THI) was calculated from the AT and $\mathrm{RH}$, according to Hahn et al. (2003):

$T H I=((\mathrm{AT} * 1.8) \pm 32)-((0.55 *(\mathrm{RH} / 100))) *(((\mathrm{AT} * 1.8) \pm 32)-58)$ 
The Heat dissipation was recorded for houses and animals, (1): heat reflection from house to animal $\left(\mathrm{HDH}, /{ }^{\circ} \mathrm{C}\right)$, and (2): from animal to the house (head, neck, abdomen, and bake) by infrared thermometer $\left(\mathrm{HDA} /{ }^{\circ} \mathrm{C}\right)$. The respiratory rate (RR) was measured by counting the flank movements for one minute. Rectal temperature $\left(\mathrm{RT},{ }^{\circ} \mathrm{C}\right)$ and skin temperature $\left(\mathrm{ST},{ }^{\circ} \mathrm{C}\right)$ were measured in centigrade units by using a clinical thermometer. Pulse rate (PP) was measured by finding the calf's artery below and slightly inside the jaw count the number of heartbeats in one minute.

Table 1. Chemical composition of concentrate feed mixture, clover hay, rice straw and the total mixed ration fed to Egyptian calves on a DM basis.

\begin{tabular}{|c|c|c|c|c|c|c|c|}
\hline \multirow{2}{*}{ Items } & \multirow{2}{*}{ DM } & \multicolumn{6}{|c|}{ Chemical composition as a DM basis } \\
\hline & & $\mathbf{O M}$ & $\mathbf{C P}$ & $\mathbf{E E}$ & $\mathbf{C F}$ & NFE & Ash \\
\hline CFM & 90.15 & 90.71 & 16.15 & 3.15 & 12.75 & 58.66 & 9.29 \\
\hline CH & 89.78 & 87.92 & 13.32 & 2.53 & 24.89 & 47.18 & 12.08 \\
\hline RS & 88.33 & 83.64 & 3.85 & 1.78 & 33.52 & 44.49 & 16.36 \\
\hline TMR & 89.71 & 88.74 & 13.12 & 2.75 & 19.33 & 53.53 & 11.26 \\
\hline
\end{tabular}

CFM, concentrate feed mixture used in formulating the experimental rations contained $24 \%$ Cotton-seed meal; $40 \%$ Wheat bran; 30\% Yellow Corn 1.5\% Lime-stone; 1 \% Sodium chloride, $0.5 \%$ vitamins and mineral mixture and $3 \%$ Molasses; CFM, concentrate feed mixture; $\mathrm{CH}$, clover hay; RS, rice straw; TMR, total mixed ration.

\section{Blood sampling}

Blood samples were collected into sterile glass tubes by jugular puncture of each animal on d 90, then every $30 \mathrm{~d}$ intervals. Five $\mathrm{ml}$ of the blood was taken; $1 \mathrm{ml}$ put in an anticoagulant bottle, by EDTA, for hematological assay. The concentration of hemoglobin $(\mathrm{Hb}, \mathrm{g} / \mathrm{dl})$ and Hematocrit value (Ht, \%) were determined by using the automatic method (automatic cell counter). The remaining 4 $\mathrm{ml}$ of blood was put into a sterile vacutainer tube without an anticoagulant for serum hormonal assay. Serum was collected by centrifugation at $1,800 \times \mathrm{g}$ for $20 \mathrm{~min}$ at $4^{\circ} \mathrm{C}$. Serum samples were stored at $-20^{\circ} \mathrm{C}$ for subsequent analysis of IGF-1 and GH concentrations by using commercial ELISA kit (Beijing Sino-UK Institute of Biological Technology, Beijing, China), according to Yang et al. (2019). Direct radioimmunoassay (RIA) technique was performed for the assessment of total serum tri-iodothyronine $\left(\mathrm{T}_{3}\right)$ concentrations. Ready antibody-coated tube kits (Total $\mathrm{T}_{3}$ RIA KIT. REF IM 1699-2013-08-14-IM3287) was used according to the procedure outlined by the manufacturer. Assessment of total testosterone concentration was performed, according to Jaffe (2012).

\section{Puberty and sexual performance}

Sexual behavior was observed for all male calves post-weaning until puberty (first collected ejaculate with motile sperm). Calves were tested weekly for libido from 8:00 to 9:00 am until puberty. The sexual desire was tested for each animal within $25 \mathrm{~min}$ by exposing calves to teaser heifer in estrus, which was randomly selected. All calves were allowed out of the collecting area without restraint to observe sexual activity towards the heifer and to examine the following criteria: first mounting without erection (stage I), mounting with $1^{\text {st }}$ erection (stage II), and first collected ejaculate containing motile sperm (stage III). Age, weight and scrotal circumference were recorded at each stage of puberty.

Observing maturation of bull calves (by recording reaction time and latency period for each animal throughout the 20-min period, according to Kridli and Al-Yacoub (2006). Semen ejaculates were collected using an artificial vagina at puberty and maturity to evaluate their semen characteristics, according to Almquist and Hale (1973). Sexually mature bulls under different housing types (CS, PS and WS) were used to inseminate an equal number of cows. Pregnancy was confirmed by rectal palpation after 60 days of insemination in nonreturned cows, and it was calculated by the following equation:

Pregnancy rate $(\%)=\frac{\text { Number of pregnant cows }}{\text { Total number of cows inseminated }} \times 100$

\section{Statistical analyses}

All results were subjected to analysis of variance procedure using general linear procedure (GLM) following SAS program. Main effects in the model 
were the housing system or age. The model used for statistical analysis was:

$$
Y_{i j k}=\mu \pm \mathrm{Ti} \pm \mathrm{Gj} \pm \mathrm{TGij} \pm \mathrm{Eijk}
$$

Where, $\mathbf{Y}=$ Experimental observation, $\boldsymbol{\mu}=$ General mean, $\mathbf{T i}=$ the effect of the housing system, $\mathbf{G j}=$ the effects of age, TGij = the effect of interaction between housing system and age, and Eijk = Experimental error of ijk observation.

\section{Results}

\section{Environmental conditions}

The environmental conditions of animal houses are presented in Table 2. Results showed that CS type had significantly $(P<0.001)$ the lowest values of AT and RH followed by PS type, while WS type recorded the highest profits. THI values were
70.97, 76.98, and 82.69 for the different housing types (CS, PS and WS), respectively (Table 2). However, THI values in WS house was the highest $(P<0.001)$ compared to other semi-open types (CS or PS).

\section{Thermo-regulatory and hematological and heat dissipation parameters}

Effects of the three housing types on calves' thermo-regulatory, hematological, and heat dissipation parameters are presented in Table 3 . CS housing type recorded the lowest $(P<0.001)$ values for thermo-regulatory parameters (RT, ST, RR and PR) followed by PS, while WS housing type had the highest profits. The same trend was obtained with $\mathrm{HDH}$ or HAD. In contrast, the levels of hematological parameters ( $\mathrm{Ht}$ and $\mathrm{Hb}$ ) were significantly $(P<0.001)$ increased with $\mathrm{CS}$, followed by PS and WS had the lowest values.

Table 2. Mean \pm SE for ambient temperature, relative humidity and temperature-humidity index under experimental housing types.

\begin{tabular}{|c|c|c|c|c|}
\hline \multirow{2}{*}{ Items } & \multicolumn{3}{|c|}{ Housing types } & \multirow{2}{*}{$P$ - Value } \\
\hline & CS & PS & WS & \\
\hline $\mathrm{AT},{ }^{\circ} \mathrm{C}$ & $26.00 \pm 0.37^{a}$ & $32.54 \pm 0.5^{b}$ & $39.40 \pm 0.84^{c}$ & 0.001 \\
\hline RH, \% & $68.60 \pm 1.85^{\mathrm{a}}$ & $74.02 \pm 1.15^{\mathrm{b}}$ & $81.80 \pm 0.79^{c}$ & 0.001 \\
\hline $\mathrm{THI}^{*}$ & $70.97 \pm 0.54^{\mathrm{a}}$ & $76.98 \pm 0.63^{b}$ & $82.69 \pm 0.76^{c}$ & 0.001 \\
\hline
\end{tabular}

$\mathrm{a}, \mathrm{b}$ and $\mathrm{c}$, means per each row with different superscripts are significantly different $(P<0.05)$. CS: semi-open type shaded roofed with concrete slab and was topped with three rows of rice straw bales and natural earthen ground with north-south direction. PS: semi-open type shaded roofed with a layer of iron sheet and natural earthen ground with west-east direction. WS: open type without shaded or roofed and exposed to the direct solar radiation and natural earthen ground with north-south direction. AT: air temperature, RH: relative humidity, THI: temperature-humidity index; ${ }^{*} \mathrm{THI}=\left(\left(\mathrm{AT}^{*} 1.8\right) \pm 32\right)-\left(\left(0.55^{*}(\mathrm{RH} / 100)\right)\right)^{*}\left(\left(\left(\mathrm{AT}^{*} 1.8\right) \pm 32\right)-58\right)$.

Table 3. Mean \pm SE for thermo-regulatory, hematological parameters and heat dissipation from house and calves of Egyptian calves under experimental housing types.

\begin{tabular}{lllll}
\hline \multirow{2}{*}{ Items } & \multicolumn{2}{l}{ Housing types } & WS & P - Value \\
\cline { 2 - 5 } & CS & PS & $39.17 \pm 0.07^{\mathrm{a}}$ & 0.001 \\
\hline $\mathrm{RT},{ }^{\circ} \mathrm{C}$ & $38.30 \pm 0.05^{\mathrm{c}}$ & $38.71 \pm 0.05^{\mathrm{b}}$ & $37.25 \pm 0.05^{\mathrm{a}}$ & 0.001 \\
$\mathrm{ST},{ }^{\circ} \mathrm{C}$ & $35.84 \pm 0.08^{\mathrm{c}}$ & $36.57 \pm 0.08^{\mathrm{b}}$ & $39.30 \pm 0.49^{\mathrm{a}}$ & 0.001 \\
$\mathrm{RR}, \mathrm{r} / \mathrm{min}$. & $28.10 \pm 1.33^{\mathrm{c}}$ & $32.10 \pm 0.47^{\mathrm{b}}$ & $104.50 \pm 1.08^{\mathrm{a}}$ & 0.001 \\
$\mathrm{PR}, \mathrm{r} / \mathrm{min}$. & $74.70 \pm 2.22^{\mathrm{c}}$ & $92.50 \pm 1.76^{\mathrm{b}}$ & $40.84 \pm 0.85^{\mathrm{a}}$ & 0.001 \\
$\mathrm{HDH},{ }^{\circ} \mathrm{C}$ & $27.25 \pm 0.47^{\mathrm{c}}$ & $34.44 \pm 0.61^{\mathrm{b}}$ & $39.92 \pm 0.58^{\mathrm{a}}$ & 0.001 \\
$\mathrm{HAD},{ }^{\circ} \mathrm{C}$ & $36.07 \pm 0.2 \mathrm{O}^{\mathrm{c}}$ & $37.39 \pm 0.43^{\mathrm{b}}$ & $29.32 \pm 0.16^{\mathrm{c}}$ & 0.001 \\
$\mathrm{Ht}, \%$ & $32.04 \pm 0.21^{\mathrm{a}}$ & $31.09 \pm 0.23^{\mathrm{b}}$ & $9.59 \pm 0.05^{\mathrm{c}}$ & 0.001 \\
$\mathrm{Hb}, \mathrm{g} / \mathrm{dl}$ & $10.41 \pm 0.07^{\mathrm{a}}$ & $10.10 \pm 0.08^{\mathrm{b}}$ & \\
\hline
\end{tabular}

$\mathrm{a}, \mathrm{b}$, and $\mathrm{c}$, means per each row with different superscripts are significantly different $(P<0.05)$. CS: semi-open type shaded roofed with concrete slab and was topped with three rows of rice straw bales and natural earthen ground with north-south direction. PS: semi-open type shaded roofed with a layer of iron sheet and natural earthen ground with west-east direction. WS: open type without shaded or roofed and exposed to the direct solar radiation and natural earthen ground with north-south direction. RT: rectal temperature, ST: skin temperature, RR: respiration rate, HDH: heat dissipation from house, HAD: heat dissipation from calves, Ht: hematocrit, Hb: hemoglobin. 


\section{GH and IGF-1 concentrations}

Serum GH and IGF-1 concentrations from 90 to 540 days under the types of experimental housing are shown in Table 4 . CS housing type had the highest $(P<0.001)$ positive effects on $\mathrm{GH}$ and IGF-1 concentrations from 90 to 540 days in comparison with PS and WS housing types, while WS housing type had the highest $(P<0.001)$ adverse effects on $\mathrm{GH}$ and IGF-1 concentrations from 90 to 540 days. The present results also indicated that there were gradual increases in IGF1 concentration with advancing age (90-540 d), while serum GH concentration followed the opposite trend of IGF-1. Where GH serum concentration was the highest at the beginning of the growth period (days 90), then decreased over time.

Table 4. Mean \pm SE for GH and IGF-1concentrations of Egyptian calves at different ages under experimental housing types.

\begin{tabular}{|c|c|c|c|c|}
\hline \multirow{2}{*}{ Age, day } & \multicolumn{3}{|l|}{ Housing types } & \multirow{2}{*}{$P$ - Value } \\
\hline & CS & PS & WS & \\
\hline \multicolumn{5}{|c|}{ GH, ng/ml* } \\
\hline D 90 & $20.46 \pm 0.42^{\mathrm{a}}$ & $20.19 \pm 0.24^{\mathrm{a}}$ & $17.33^{ \pm 0.68^{b}}$ & 0.001 \\
\hline D180 & $15.14 \pm 0.35^{\mathrm{a}}$ & $13.56 \pm 0.18^{b}$ & $11.27 \pm 0.63^{c}$ & 0.001 \\
\hline D270 & $12.16 \pm 0.09^{\mathrm{a}}$ & $10.24 \pm 0.23^{b}$ & $9.07 \pm 0.26^{c}$ & 0.001 \\
\hline D36o & $10.48 \pm 0.17^{\mathrm{a}}$ & $8.89 \pm 0.29^{b}$ & $6.92 \pm 0.30^{c}$ & 0.001 \\
\hline D450 & $8.03 \pm 0.10^{a}$ & $7 \cdot 32 \pm 0.16^{b}$ & $5.83 \pm 0.14^{c}$ & 0.001 \\
\hline D540 & $5.92 \pm 0.23^{\mathrm{a}}$ & $5.05^{ \pm 0.18^{b}}$ & $4.51 \pm 0.18^{b}$ & 0.001 \\
\hline \multicolumn{5}{|c|}{ IGF-1, ng/ml* } \\
\hline D 90 & $299.20 \pm 6.47^{\mathrm{a}}$ & $266.40 \pm 7.72^{\mathrm{b}}$ & $236.60 \pm 5.69^{c}$ & 0.001 \\
\hline D180 & $345.00 \pm 13.54^{\mathrm{a}}$ & $317.20 \pm 14.23^{\mathrm{a}}$ & $306.40 \pm 10.48^{a}$ & 0.125 \\
\hline D270 & $424.40 \pm 7.94^{\mathrm{a}}$ & $416.40 \pm 20.57^{\mathrm{a}}$ & $384.20 \pm 19.46^{\mathrm{a}}$ & 0.240 \\
\hline D36o & $486.00 \pm 8.89^{a}$ & $455.00 \pm 18.00^{\mathrm{ab}}$ & $416.60 \pm 14.91^{b}$ & 0.014 \\
\hline D450 & $539.60 \pm 5.95^{\mathrm{a}}$ & $476.00 \pm 18.15^{\mathrm{ab}}$ & $450.20 \pm 15.06^{b}$ & 0.001 \\
\hline D540 & $568.00 \pm 11.99^{\mathrm{a}}$ & $501.20 \pm 18.89^{b}$ & $482.60 \pm 13.86^{\mathrm{b}}$ & 0.003 \\
\hline
\end{tabular}

$\mathrm{a}, \mathrm{b}$, and $\mathrm{c}$, means per each row with different superscripts are significantly different $(P<0.05)$. CS: semi-open type shaded roofed with concrete slab and was topped with three rows of rice straw bales and natural earthen ground with north-south direction. PS: semi-open type shaded roofed with a layer of iron sheet and natural earthen ground with west-east direction. WS: open type without shaded or roofed and exposed to the direct solar radiation and natural earthen ground with north-south direction. * Hormones concentration for each animal were calculated as the average of measurements made in six samples collected at $90 \mathrm{~d}$ intervals from 90 to $540 \mathrm{~d}$ of age.

\section{Feed conversion}

Total dry matter intake (TDMI) and body weight (BW) of Egyptian calves from 90 to 540 days were significantly higher $(P<0.001)$ with the CS housing type compared to other housing types (PS and WS). Also, the CS housing type showed significant $(P<0.001)$ improvement in average daily gain (ADG) and feed conversion (FC) from 90 to 540 days (Table 5). Results indicated that there were gradual increases in TDMI, BW, ADG, and FC of experimental animals with advancing age (90 to $540 \mathrm{~d}$ ) under the tested housing types.

Table 6 summarized the partial correlations among age, BW, ADG, GH, and IGF-1 concentrations. Closed positive correlations were observed among age, BW, ADG and IGF-1 concentrations $(P<0.01)$; values of $r$ were $0.89,0.91$ and 0.64 for age, BW and ADG, respectively. However, serum GH concentration recorded negative correlations with the previous traits. The correlation between serum $\mathrm{GH}$ and IGF-1 was negative.

\section{Reproductive performance}

Age and weight at the different stages of puberty for Egyptian calves are presented in Fig. 1(a). Under CS housing type, calves reached earlier age and heavier weight at puberty than calves housed under the other two housing types (PS and WS). However, there were no significant differences between CS and PS housing types when compared with the WS housing type. 
Table 5. Mean \pm SE for total dry matter intake (TDMI), body weight (BW), average daily gain (ADG) and feed conversion (FC) of Egyptian calves at different ages under experimental housing types.

\begin{tabular}{|c|c|c|c|c|}
\hline \multirow{2}{*}{ Age, day } & \multicolumn{3}{|c|}{ Housing types } & \multirow{2}{*}{$P$ - Value } \\
\hline & CS & PS & WS & \\
\hline \multicolumn{5}{|l|}{ TDMI, kg } \\
\hline D 90 & $2.14 \pm 0.01^{\mathrm{a}}$ & $2.05 \pm 0.01^{\mathrm{b}}$ & $2.08 \pm 0.01^{b}$ & 0.001 \\
\hline D 180 & $3.81 \pm 0.01^{\mathrm{a}}$ & $3.66 \pm 0.01^{c}$ & $3.74 \pm 0.02^{\mathrm{b}}$ & 0.001 \\
\hline D 270 & $5.53 \pm 0.01^{\mathrm{a}}$ & $5.40 \pm 0.03^{b}$ & $5.45^{ \pm 0.01^{\mathrm{b}}}$ & 0.001 \\
\hline D 360 & $7.26 \pm 0.03^{\mathrm{a}}$ & $7.17 \pm 0.02^{\mathrm{b}}$ & $7.23 \pm 0.02^{\mathrm{ab}}$ & 0.026 \\
\hline D 450 & $9.10 \pm 0.02^{\mathrm{a}}$ & $8.95 \pm 0.04^{b}$ & $8.79 \pm 0.05^{c}$ & 0.001 \\
\hline D 540 & $10.88 \pm 0.05^{\mathrm{a}}$ & $10.60 \pm 0.05^{b}$ & $10.43 \pm 0.10^{b}$ & 0.001 \\
\hline \multicolumn{5}{|l|}{ BW, kg } \\
\hline D 90 & $85.40 \pm 0.42^{\mathrm{a}}$ & $82.00 \pm 0.37^{b}$ & $78.40 \pm 0.42^{c}$ & 0.001 \\
\hline D 180 & $152.20 \pm 0.54^{\mathrm{a}}$ & $146.40 \pm 0.42^{b}$ & $141.00 \pm 0.73^{c}$ & 0.001 \\
\hline D 270 & $221.00 \pm 0.5^{\mathrm{a}}$ & $217.10 \pm 4.19^{b}$ & $205.60 \pm 0.55^{c}$ & 0.001 \\
\hline D 360 & $290.40 \pm 1.11^{\mathrm{a}}$ & $281.20 \pm 0.48^{b}$ & $272.80 \pm 0.70^{c}$ & 0.001 \\
\hline D 450 & $361.80 \pm 1.40^{\mathrm{a}}$ & $350.80 \pm 0.75^{\mathrm{b}}$ & $331.60 \pm 1.98^{c}$ & 0.001 \\
\hline D 540 & $435.00 \pm 2.22^{a}$ & $421.60 \pm 0.99^{b}$ & $393.40 \pm 3.74^{c}$ & 0.001 \\
\hline \multicolumn{5}{|l|}{ ADG, kg } \\
\hline D 90 & $0.720 \pm 0.01^{\mathrm{a}}$ & $0.680 \pm 0.01^{b}$ & $0.640 \pm 0.01^{c}$ & 0.001 \\
\hline D 180 & $0.740 \pm 0.05^{b}$ & $0.720 \pm 0.03^{\mathrm{ab}}$ & $0.700 \pm 0.07^{b}$ & 0.015 \\
\hline D 270 & $0.760 \pm 0.01^{\mathrm{a}}$ & $0.740 \pm 0.01^{b}$ & $0.720 \pm 0.01^{c}$ & 0.001 \\
\hline D 360 & $0.770 \pm 0.02^{\mathrm{a}}$ & $0.760 \pm 0.01^{\mathrm{a}}$ & $0.750 \pm 0.01^{\mathrm{a}}$ & 0.374 \\
\hline D 450 & $0.790 \pm 0.01^{a}$ & $0.770 \pm 0.01^{a}$ & $0.650 \pm 0.02^{b}$ & 0.001 \\
\hline D 540 & $0.810 \pm 0.01^{\mathrm{a}}$ & $0.790 \pm 0.01^{\mathrm{a}}$ & $0.690 \pm 0.02^{b}$ & 0.001 \\
\hline \multicolumn{5}{|c|}{ FC, DM/gain } \\
\hline D 90 & $2.97 \pm 0.01^{\mathrm{c}}$ & $3.02 \pm 0.01^{b}$ & $3.23 \pm 0.01^{\mathrm{a}}$ & 0.001 \\
\hline D 180 & $5.13 \pm 0.05^{\mathrm{b}}$ & $5.12 \pm 0.03^{b}$ & $5.38 \pm 0.07^{\mathrm{a}}$ & 0.006 \\
\hline D 270 & $7.23 \pm 0.07^{b}$ & $7.30 \pm 0.09^{b}$ & $7.59 \pm 0.06^{a}$ & 0.008 \\
\hline D 360 & $9.44 \pm 0.17^{\mathrm{a}}$ & $9.47 \pm 0.11^{\mathrm{a}}$ & $9.69 \pm 0.10^{\mathrm{a}}$ & 0.354 \\
\hline D 450 & $11.47 \pm 0.07^{\mathrm{b}}$ & $11.57 \pm 0.06^{b}$ & $13.50 \pm 0.30^{\mathrm{a}}$ & 0.001 \\
\hline D 540 & $13.38 \pm 0.13^{b}$ & $13.47 \pm 0.05^{\mathrm{b}}$ & $15.25 \pm 0.36^{\mathrm{a}}$ & 0.001 \\
\hline
\end{tabular}

$\mathrm{a}, \mathrm{b}$, and $\mathrm{c}$, means per each row with different superscripts are significantly different $(P<0.05)$. CS: semi-open type shaded roofed with concrete slab and was topped with three rows of rice straw bales and natural earthen ground with north-south direction. PS: semi-open type shaded roofed with a layer of iron sheet and natural earthen ground with west-east direction. WS: open type without shaded or roofed and exposed to the direct solar radiation and natural earthen ground with north-south direction.

Table 6. Correlation between age, body weight (BW), average daily gain (ADG), GH, and IGF-1 concentrations.

\begin{tabular}{lllll}
\hline Items & ADG & BW & IGF-1 & GH \\
\hline Age & $0.457^{* * *}$ & $0.996^{* * *}$ & $0.890^{* * *}$ & $-0.918^{* *}$ \\
GH & $-0.361^{* *}$ & $-0.898^{* *}$ & $-0.779^{* *}$ & \\
IGF-1 & $0.635^{* * *}$ & $0.908^{* *}$ & & \\
BW & $0.521^{* *}$ & & & \\
\hline
\end{tabular}

${ }^{* *}$ Correlation is significant at the 0.01 level (2-tailed); ${ }^{*}$ Correlation is significant at the 0.05 level (2-tailed).

Tests circumference of pubertal calves significantly $(P<0.001)$ increased under CS compared to PS and WS housing types (Fig. 1b). Additionally, serum testosterone levels of pubertal calves recorded the highest values under the CS housing type, followed by PS and WS that had the lowest values (Fig. 1b).
Fig. 1(c) showed that serum GH and IGF-1 concentrations for calves in the different stages of puberty were influenced by the housing type under climatic conditions in middle Egypt. Results showed that IGF-1 concentrations, especially in the third stage of puberty, were significantly $(P<0.001)$ 
higher for calves under CS housing type compared to the values of PS or WS housing types. The same trend was obtained with the values of the $\mathrm{GH}$ hormone. The concentrations of IGF-1 and GH under CS, PS and WS housing types were 466, 449 and $435 \mathrm{ng} / \mathrm{ml}$ for IGF-1 and 9.0, 7.7 and 6.8 $\mathrm{ng} / \mathrm{ml}$ for $\mathrm{GH}$, respectively. The present results also indicate that there are gradual increases in IGF-1 concentration with the advancing stage of puberty, while serum GH concentration followed the opposite trend of IGF-1. Where GH serum concentration was the highest at the first stage of puberty, then decreased with advancing stage of puberty.

(a)

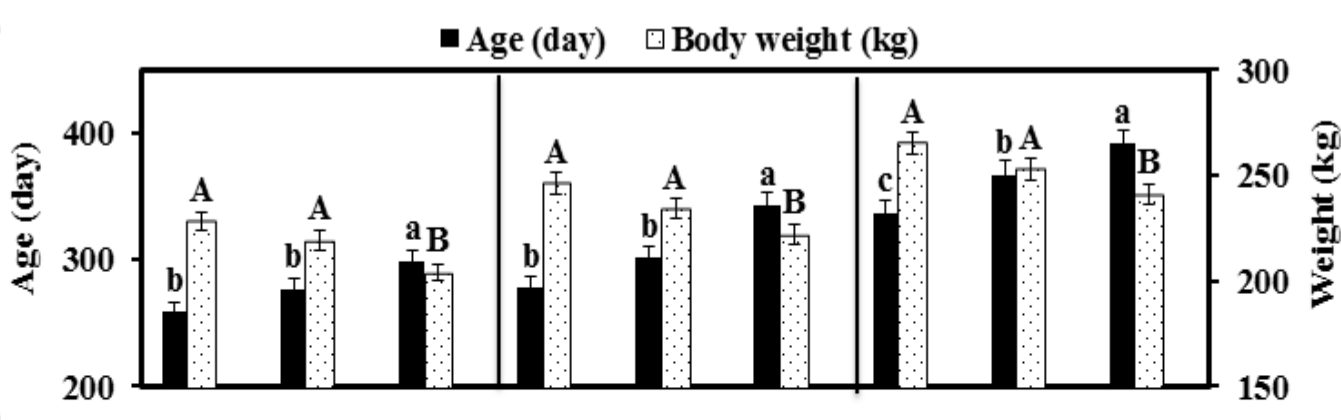

(b)

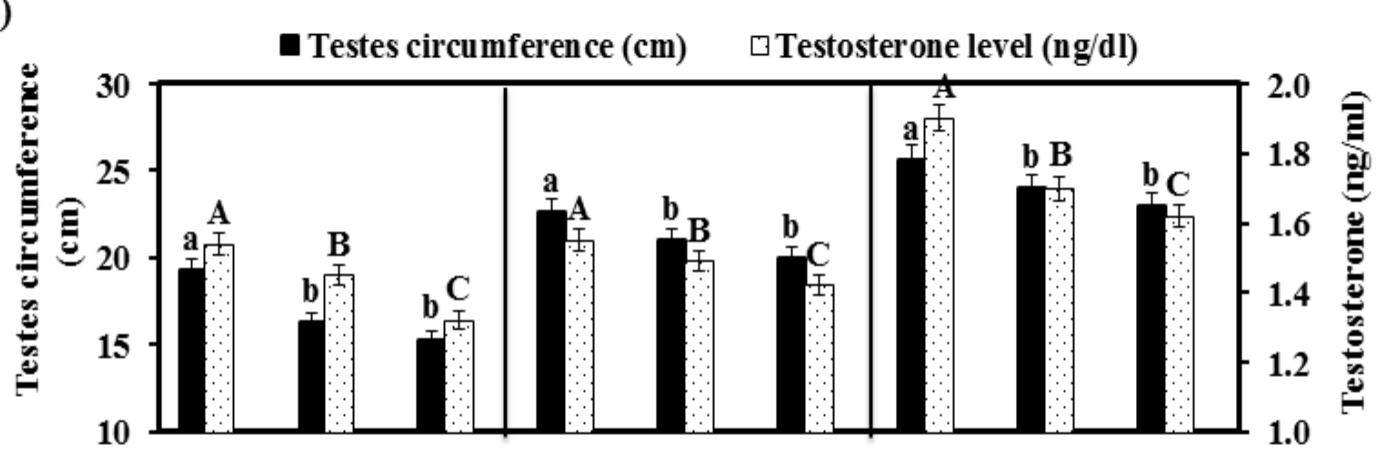

(c)

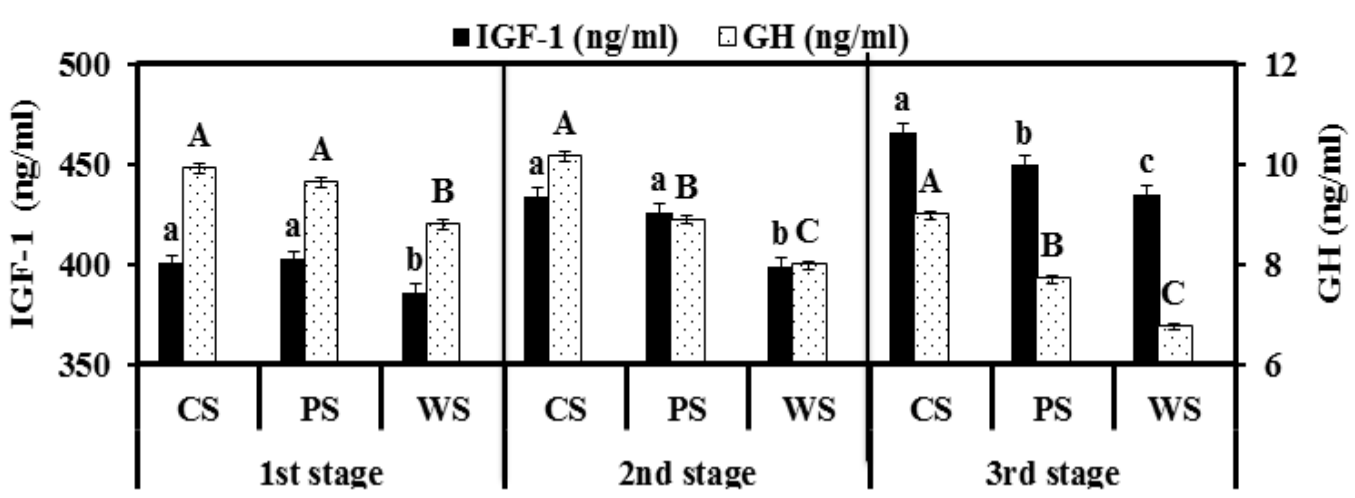

Fig. 1: Reproductive parameters at the puberty stages of Egyptian calves under experimental housing types. Different small or capital letters represent a significant difference among experimental housing types $(P<0.05)$. CS: semi-open type shaded roofed with concrete slab and was topped with three rows of rice straw bales and natural earthen ground with north-south direction. PS: semi-open type shaded roofed with a layer of iron sheet and natural earthen ground with westeast direction. WS: open type without shaded or roofed and exposed to the direct solar radiation and natural earthen ground with north-south direction. 1st stage: 1st mounting without an erection. 2nd stage: 1st mounting with erection. 3rd stage: 1st ejaculation, puberty.

Sexual activity of bull calves under different housing types are presented in Fig. 2 (a). The reaction time and latency period during the maturity of bull calves were significantly $(P<0.01)$ decreased with CS and PS compared to WS housing types. The shortest reaction time (5.2 and $5.2 \mathrm{~min}$ ) for ejaculation recorded under CS and PS housing types, respectively, while the longest was 
being under WS (6.9 $\mathrm{min})$. The latency period showed an exactly similar trend as that of reaction time. The pregnancy rate was significantly $(P<$
0.001) higher with bull calves of CS and PS housing types (79 and $72 \%$ ) compared to bull calves of WS (62\%) housing type (Fig. 2b). (a)

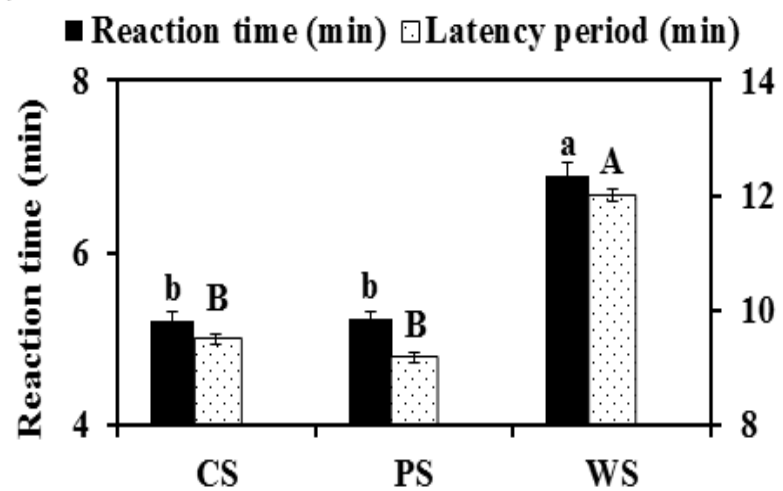

(b)

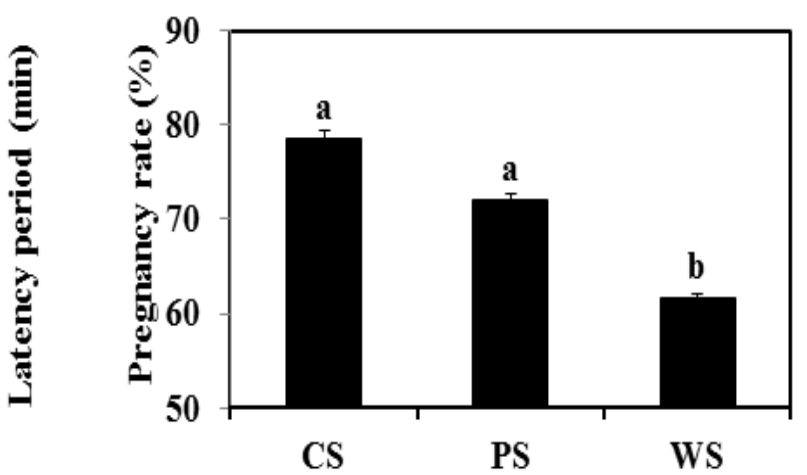

Fig. 2: Libido (a) and pregnancy rate (b) of Egyptian maturity calves under experimental housing types. Different small or capital letters represent a significant difference among experimental housing types $(P<$ 0.05). CS: semi-open type shaded roofed with concrete slab and was topped with three rows of rice straw bales and natural earthen ground with north-south direction. PS: semi-open type shaded roofed with a layer of iron sheet and natural earthen ground with west-east direction. WS: open type without shaded or roofed and exposed to the direct solar radiation and natural earthen ground with north-south direction.

Table 7. Some physical semen characteristics at puberty and maturity of Egyptian calves under experimental housing types.

\begin{tabular}{|c|c|c|c|c|}
\hline \multirow{2}{*}{ Semen characteristics } & \multicolumn{3}{|l|}{ Housing types } & \multirow{2}{*}{$P$. value } \\
\hline & $\mathbf{C S}$ & PS & WS & \\
\hline \multicolumn{5}{|l|}{ At puberty } \\
\hline Seminal volume (ml) & $1.78 \pm 0.05^{\mathrm{a}}$ & $1.32 \pm 0.08^{\mathrm{b}}$ & $1.16 \pm 0.07^{\mathrm{c}}$ & 0.001 \\
\hline Semen pH & $6.94 \pm 0.08^{a}$ & $6.92 \pm 0.05^{\mathrm{a}}$ & $7.10 \pm 0.07^{\mathrm{a}}$ & 0.134 \\
\hline Sperm concentration/ml $\left({\left.\mathrm{x} 10^{6}\right)}^{6}\right.$ & $424.00 \pm 10.73^{a}$ & $389.40 \pm 8.47^{b}$ & $318.00 \pm 7.93^{c}$ & 0.001 \\
\hline Motile sperm/Ejac. $\left({\left.\mathrm{x} 10^{6}\right)}\right.$ & $271.70 \pm 20.5^{6^{a}}$ & $149.06 \pm 12.84^{b}$ & $85 \cdot 58 \pm 5.18^{c}$ & 0.001 \\
\hline Abnormal sperm (\%) & $38.60 \pm 1.11^{\mathrm{b}}$ & $42.00 \pm 1.06^{\mathrm{a}}$ & $47.80 \pm 1.87^{\mathrm{a}}$ & 0.001 \\
\hline \multicolumn{5}{|l|}{ At maturity } \\
\hline Seminal volume (ml) & $2.98 \pm 0.05^{\mathrm{a}}$ & $2.28 \pm 0.06^{b}$ & $1.92 \pm 0.04^{c}$ & 0.001 \\
\hline Motility (\%) & $83.20 \pm 1.25^{\mathrm{a}}$ & $77.80 \pm 0.79^{b}$ & $71.60 \pm 0.84^{c}$ & 0.001 \\
\hline Motile sperm/Ejac. (x109) & $4.17 \pm 0.18^{\mathrm{a}}$ & $2.32 \pm 0.09^{b}$ & $1.50 \pm 0.06^{c}$ & 0.001 \\
\hline Abnormal sperm (\%) & $15.60 \pm 0.76^{b}$ & $16.80 \pm 0.85^{\mathrm{a}}$ & $20.40 \pm 0.76^{a}$ & 0.049 \\
\hline
\end{tabular}

$\mathrm{a}, \mathrm{b}$, and c, means per each row with different superscripts are significantly different $(P<0.05)$. CS: semi-open type shaded roofed with concrete slab and was topped with three rows of rice straw bales and natural earthen ground with north-south direction. PS: semi-open type shaded roofed with a layer of iron sheet and natural earthen ground with west-east direction. WS: open type without shaded or roofed and exposed to the direct solar radiation and natural earthen ground with north-south direction. 
Table 7 illustrated some physical semen characteristics for the experimental bull calves at puberty and maturity under the experimental housing types, especially motility, semen $\mathrm{pH}$, sperm concentration, motile sperm, and abnormal sperm (\%). The differences in average volume (ml) of semen among animals under the experimental housing types were highly significant $(P<0.001)$. The values were highest for CS type group, followed by PS then WS types that recorded the lowest one. A similar trend was obtained for motility, sperm concentration, and motile sperm. Abnormal sperm percentage values are heading in the opposite direction to previous parameters, while there were no significant differences among animals under the experimental housing types in the semen $\mathrm{pH}$.

\section{Discussion}

This study aimed to evaluate the different housing types applied in middle Egypt to determine which is more suitable for accommodating Egyptian calves. The suitability of each type of housing depends on the available climatic conditions such as AT, RH, and THI, which can modify GH and IGF-1 levels in Egyptian calves, and consequently affect the growth and reproductive performance.

Data in the current study revealed that CS type is more appropriate in terms of AT and RH as well as THI. This type recorded the lowest values of AT, RH and THI followed by PS type. However, WS type was the least appropriate as it recorded the highest values of AT, RH, and THI, so it was terrible in controlling micro-environmental conditions around animals under middle Egypt. These results are in accordance with Mohamed et al. (2017) and Ibrahim et al. (2018). Omran et al. (2019) reported that the THI value of 72 and below considered as no heat stress, $73-77$ as mild heat stress, $78-89$ as moderate heat stress, and above 90 as severe heat stress. THI index still the best indicator for stress under natural environmental conditions. Additionally, any improvement in THI would be ideally beneficial as a basis for the continuous development of biological responses and the representation of the consequences of primary factors in energy exchange (Omran and Hamdon, 2018).

As a result of the climatic variations among the tested housing types (CS, PS and WS) in this study, thermo-regulatory (RT, ST, RR and PR), hematological ( $\mathrm{Ht}$ and $\mathrm{Hb}$ ) and heat dissipation (HDH and HAD) parameters were also affected. These parameters recorded the lowest values with CS, followed by PS, and the highest values were recorded with WS. While hematocrit and hemoglobin recorded the most top benefits with CS followed by PS, and the lowest values were recorded with WS. Where the animal resort to increasing the $\mathrm{RR}$ under heat stress to dissipate the excess heat from its body by evaporating more moisture in the expired air, which represents about 30\% of the total heat dissipation (Omran et al., 2019). High AT, RH, and THI in the experimental housing types affected the hematological responses of animals, which consistency with the results of Abozed (2014). Kamal et al. (1984) explained that under hot climatic conditions, the increase of RR might lead to an increase in oxygen transportation for heatstressed animals, accompanied by a decrease in plasma protein and some trace elements such as cobalt, iron, and copper, which are essential minerals for the synthesis of hemoglobin, which reduces the proportion of hemoglobin. The present results indicated that CS housing considered the best type compared with others under the climatic condition of middle Egypt. This type used to protect surfaces from direct solar radiation reduces the temperature of the roof, which has a positive effect on the micro-environment within the animal, and this reflected on animal efficiency to maintain their biological activity.

In this study, the climatic differences of the tested housing types influenced the hormonal levels of GH and IGF-1 of animals. Serum GH and IGF-1 concentrations under CS type increased linearly compared to other housing types (PS and WS). These results may be related to that CS housing type was more suitable in the environmental condition in terms of AT and RH as well as THI and thus had no heat stress (Table 2) compared to other housing types. There are numerous climate stresses like heat, cold, rain, wind, and humidity, which can alter the endocrine system and animal performance such as animals' natural cycle and reproductive system (Gaughan and Cawsell-Smith, 2015). These results are supported by Tao and Dahl (2013), who reported that a response was observed on cold or unheated-stress cows mediated by the enhanced $\mathrm{GH}$ concentrations compared with heat-stressed cows. 
Furthermore, the current results indicated that there are gradual increases in serum IGF-1 concentration with advancing age (90-540 d) of animals, while serum GH concentration followed the opposite trend of IGF-1. The obtained results are in agreement with the previous study reported that the secretion of $\mathrm{GH}$ decreased with advancing age in Holstein bulls (Istasse et al., 1990). IGF-1 concentration was increased with advancing age, while GH concentration tended to decrease for Holstein steers as reported by Torrentera et al. (2009).

The housing types also affected TDMI, BW, ADG, and FC of Egyptian calves. Gradual improvement in TDMI, BW ADG and FC were noticed with advancing age (90-540 d) for animals under CS housing type. It is worth noting that the improvements in the previous parameters are accompanied by the improvement of both $\mathrm{GH}$ and IGF-1 levels. Where, CS type had a positive effect of increasing GH and IGF-1 concentrations compared with other housing types (PS and WS), which led to increasing TDMI, BW, and ADG. Klindt et al. (1998) indicated that GH enhances the deposition of lean tissue and increases feed efficiency in farm animals. Also, GH in animal species such as pigs or cattle not only improves growth performance and milk production but also improves production efficiency in practice and metabolism (Brown et al., 2008). Besides, IGF-1 plays a vital role in some physiological processes, enhances feed conversion, and also increases protein synthesis (Gao et al., 2006).

Moreover, the data obtained in Table 6 confirm that there are closed correlations among age, BW, ADG, GH, and IGF-1 concentrations. These correlations were consistently positive and generally high throughout the performance during the experimental period. However, serum GH concentration recorded negative associations with previous traits. These results are in agreement with Torrentera et al. (2009). The liver is the main production site of circulating IGF-1 under GH control. Therefore it was surprising to observe a reduction in $\mathrm{GH}$ production with an increase in IGF-1 concentration (Istasse et al., 1990).

In the current study, CS and PS housing types were effective in enhancing fertility in general. Results indicated that the weight and age of pubertal calves in CS and PS groups were significantly heavier and younger than those of the WS group. The improvement in puberty parameters of calves under CS or PS housing types may be related to the improvement of TDMI and energy intake (Table 5). The data provided indicated that there had accelerated age with heavier body weight and larger testicle size. These features are associated with each other. This positive difference was reflected in the increased levels of serum testosterone (Fig. 1b). Abd El-Moty et al. (2001) reported a closed positive correlation among body weight, testes circumference, and testosterone levels in both Buffalo and Friesian bulls. Testosterone levels were low at the early stages of the sexual development of animals under different experimental housing types and gradually increased with advancing age (Fig. 1b). The changes in body weight and testicular circumference by aging might be attributed to active testosterone secretion.

Animals with bigger testes produce more testosterone levels. The increase in testosterone concentration throughout puberty was much better with CS than PS and WS housing types. The level of nutrition and daily gain of animals in the CS group could influence scrotal circumference (Mohamed et al., 2016). Furthermore, heavier and younger calves of CS compared to calves under PS and WS housing types may be related to the corresponding peak in levels of GH and IGF-1 (Fig. 1c). Shirley et al. (2001) found that heavier ewes tended to produce more $\mathrm{GH}$ and attained puberty earlier than lighter ewes. IGF-1 binds to IGF-factor that binding protein-3 to influence the development, growth, and animals' reproduction (Othman et al., 2014). The increase of GH and IGF-1 levels might relate to an increase in total dry matter, energy intake, and improved feed conversion. A recent study showed that an increment in the level of dietary energy could significantly enhance $\mathrm{FC}, \mathrm{GH}$, and IGF-1 in cattle (Zhang et al., 2019). On the other hand, the improvement in reaction time and latency period in CS and PS groups may be attributed to increasing testosterone levels in these groups.

All physical properties of semen, except semen $\mathrm{pH}$ at puberty and maturity, under CS type, were significantly higher compared to PS and WS types. This improvement in semen properties can be associated with increased body weight and testes 
circumference, where they have higher values for CS than PS or WS (Figs. 1a and 1b). Additionally, testosterone had higher values with CS than PS or WS (Fig. 1b). Testosterone plays a major role in the development of reproductive organs and their functions (Hafez and Hafez, 2013). Also, Kishk (2008) indicated a significant correlation between testosterone and all reaction time, semen volume, sperm motility, and sperm concentration in the rams. This result is in agreement with Mohamed et al. (2016), who reported that all physical semen characteristics at puberty and sexual maturity were significantly higher for rams in which the testosterone concentration increased. Also, this improvement in semen properties and sexual performance in bull calves under CS housing type can be associated with increased GH and IGF-1 concentrations (Fig. 1c) and their positive correlation with testosterone level. This expectation was supported by Kumar et al. (2016), who indicated that bull calves responded to the increase from $\mathrm{GnRH}$ by secreting significant amounts of testosterone.

Ultimately it can conclude that sexual performance and semen quality were better for CS-related calves subjected to low AT, RH, and THI followed by the calves kept under PS type with moderate heat stress. In contrast, calves belong to WS type with high heat stress recorded the lowest reproductive parameters. These results are in accordance with many previous studies (Mohamed et al., 2017; Ibrahim et al., 2018; Omran and Hamdon, 2018; Omran et al., 2019).

\section{Conclusion}

From the perspective of previous results, it could conclude that the semi-open type shaded roofed with concrete slab and topped with three rows of rice straw bales provides more comfortable climatic conditions for Egyptian calves than other housing types under middle Egypt conditions. Also, data of IGF-1 concentration may be a useful aid as criteria for selection to improve growth and reproductive efficiency. Further studies will be needed in the future to compare between more comfortable housing types and their relationship on the micro-environment within the animal and its impact on milk production and its components, also, their relationship with GH and IGF-1 concentrations.

\section{Conflict of interest statement}

Authors declare that they have no conflict of interest.

\section{Ethics statement}

All animal procedures were performed in accordance with the standards set forth guidelines for the care and use of experimental animals by the Animal Ethics Committee of APRI, ARC, Egypt.

\section{References}

Abd El-Moty, A., Abd El-Hakeam, A., El-Barody, M., El-Feel, F., Baiomy, A., 2001. Reproductive response of buffalo and Friesian male bulls subjected to sexual biostimulant. Egyp. Soc. Anim. Reprod. Fert. Thirteenth Ann. Cong., Giza. 159, 22-26.

Abozed, G., 2014. Impact of housing types on performance of small ruminant under Upper Egypt conditions: Ph. D. Thesis, Fac. Agric., Assiut Univ., Assiut, Egypt.

Almquist, J., Hale, E., 1973. An approach to the measurement of sexual behaviour and semen production of dairy bulls. Third International Congress of Animal Reproduction Durban, Singapore, Sydney, Toronto, Wellington.

Bhimte, A., Thakur, N., Lakhani, N., Yadav, V., Khare, A., Lakhani, P., 2018. Endocrine changes in livestock during heat and cold stress. J. Pharmacogn. Phytochem. 7(4), 127132.

Bousquet, D., Bouchard, E., Du Tremblay, D., 2004. Decreasing fertility in dairy cows: myth or reality? Med. Veter. Quebec. 34, 59-60.

Brown, P. A., Bodles-Brakhop, A. M., Draghia-Akli, R., 2008. Effects of plasmid growth hormonereleasing hormone treatment during heat stress. DNA Cell Biol. 27(11), 629-635.

Gao, X., Xu, X., Ren, H., Zhang, Y., Xu, S., 2006. The effects of the GH, IGF-I and IGF-IBP3 gene on growth and development traits of Nanyang cattle in different growth period. Yi chuan-Heredit. 28(8), 927-932.

Gaughan, J., Cawdell-Smith, A., 2015. Impact of climate change on livestock production and reproduction. Climate change Impact on livestock: adaptation and mitigation: Springer. pp. 51-6o.

Hafez, E.S.E., Hafez, B., 2013. Reproduction in 
farm animals: John Wiley \& Sons.

Hahn, G., Mader, T., Eigenberg, R., 2003. Perspective on development of thermal indices for animal studies and management. EAAP Technic. Ser. 7, 31-44.

Humam, A. M., Loh, T. C., Foo, H. L., Samsudin, A. A., Mustapha, N. M., Zulkifli, I., Izuddin, W. I., 2019. Effects of feeding different Postbiotics produced by Lactobacillus plantarum on growth performance, carcass yield, intestinal morphology, gut microbiota composition, immune status, and growth gene expression in broilers under heat stress. Animals (Basel). 9, 644 .

Ibrahim, M., Ibrahim, E., Mohamed, M., 2018. Productive performance of Ossimi ewes postlambing as affected by selenium yeast and/or vitamin $\mathrm{E}$ supplemented rations under two different housing types. J. Anim. Poult. Prod. 9(1), 1-7.

Istasse, L., Van Eenaeme, C., Evrard, P., Gabriel, A., Baldwin, P., Maghuin-Rogister, G., Bienfait, J-M., 1990. Animal performance, plasma hormones and metabolites in Holstein and Belgian Blue growing-fattening bulls. J. Ani. Sci. 68(9), 2666-2673.

Jaffe, B., 2012. Methods of Hormone Radioimmunoassay. Elsevier, 1070 p.

Kamal, T., Meherz, A., El-Shinnawy, M., AboulNaga, A., 1984. Effect of high environmental temperature on mineral metabolism in Friesian cattle. Proc. 1th Egyptian-British. Conf. Anim. Poul. Prod., Zagazig University, Egypt.

Kishk, W., 2008. Interrelationship between ram plasma testosterone level and some semen characteristics. Slovak J. Anim. Sci. 41(2), 67-71.

Klindt, J., Yen, J. T., Buonomo, F., Roberts, A., Wise, T., 1998. Growth, body composition, and endocrine responses to chronic administration of insulin-like growth factor I and (or) porcine growth hormone in pigs. J. Anim. Sci. 76(9), 2368-2381.

Kridli, R. T., Al-Yacoub, A. N., 2006. Sexual performance of Awassi ram lambs reared in different sex composition groups. Appl. Anim. Behav. Sci. 96(3-4), 261-267.

Kumar, B. B., Pandita, S., Prakash, B., Mallick, S., Mili, B., 2016. Responsiveness of prepubertal crossbred bull calves to exogenous GnRH and its impact on reproductive hormones under tropical conditions. SpringerPlus 5(1), 288.

Mohamed, M., Gomaa, A., Ibrahim, E., Saba, F. E.,
El-Badawy, A., El Giziry, A., 2016. Sexual activity and reproductive performance of Ossimi sheep fed biologically treated rice straw by enzymes or effective microorganisms. Egypt. J. Sheep Goats Sci. 11(3), 1-16.

Mohamed, M., Ibrahim, E., AM AE-M., 2017. Effect of selenium yeast and/or vitamin e supplemented rations on some physiological responses of post-lambing Ossimi ewes under two different housing systems. Egypt. J. Nutr. Feeds. 20(3), 361-378.

Munoz, A., Trigo, P., Riber, C., Malonda, V., Castejon, F., 2011. A study of serum insulinlike growth factor type 1 (IGF-1) concentrations in resting untrained Andalusian horses: influence of age and gender. Vet. Med. 56(5), 231-242.

NRC, 2001. Nutrient requirements of dairy cattle. $7^{\text {th }}$ Ed. National Academy of Sciences. Washington, DC, USA.

Omran, F., Abd El-Rahim, S., Fooda, T., 2019. Physiological and productive performance of Egyptian buffaloes and cows under different housing systems and environmental conditions in the North Delta region. Proceeding of the 1st International Conference of Animal Production, September 10-14, Sharm El Sheikh City, Egypt.

Omran, F., Hamdon, H., 2018. Transportation, adaptive and productive performance of transported buffalo herd in new environment. J. Anim. Poult. Prod. 9(3), 191-196.

Othman, O. E., Alam, S. S., El-Aziem, S. H. A., 2014. Single nucleotide polymorphism in Egyptian cattle insulin-like growth factor binding protein-3 gene. J. Genet. Eng. Biotechnol. 12(2), 143-147.

Shirley, K., Hernandez, J., Hallford, D., Thomas, M., 2001. Serum luteinizing hormone, growth hormone and insulin-like growth factor-I after releasing hormone challenge in prepubertal ewe lambs selected for twinning. Theriogenol. 56(5), 867-877.

Silva, R.G.D., Morais, D.A.E.F., Guilhermino, M. M., 2007. Evaluation of thermal stress indexes for dairy cows in tropical regions. Rev. Bras. Zootec. 36(4), 1192-1198.

Tao, S., Dahl, G., 2013. Invited review: Heat stress effects during late gestation on dry cows and their calves. J. Dairy Sci. 96(7), 4079-4093.

Tilbrook, A. J., Turner, A. I., Clarke, I. J., 2000. Effects of stress on reproduction in non-rodent 
mammals: the role of glucocorticoids and sex differences. Rev. Reprod. 5(2), 105-113.

Torrentera, N., Cerda, R., Cervantes, M., Garces, P., Sauer, W., 2009. Relationship between blood plasma IGF-1 and GH concentrations and growth of Holstein steers. Arch. Latinoamer. Prod. Anim. 17(1-2), 37-41.

Yang, C., Zhang, J., Ahmad, A. A., Bao, P., Guo, X., Long, R., Ding, X., Yan, P., 2019. Dietary energy levels affect growth performance through growth hormone and insulin-like growth factor 1 in yak (Bos grunniens). Animals. 9(2), 39.

Zhang, H., Zhang, X., Wang, Z., Dong, X., Tan, C., Zou, H., Peng, Q., Xue, B., Wang, L., Dong, G., 2015. Effects of dietary energy level on lipid metabolism- related gene expression in subcutaneous adipose tissue of Yellow breed $\times$ Simmental cattle. Anim. Sci. J. 86(4), 392-400.

\section{How to cite this article:}

Abd El-Hafeez, A. M., Zahed, S. M., Mohamed, M. Y., 2020. Association between Egyptian calves performance and growth hormone and IGF-1 levels under different housing types. Int. J. Curr. Res. Biosci. Plant Biol. 7(7), 22-34. doi: https://doi.org/10.20546/ijcrbp.2020.707.002 